\title{
SCREENING SURVEY OF OCULAR, NASAL, RESPIRATORY AND SKIN SYMPTOMS IN MANICURISTS IN POLAND
}

\section{MARTA KIEĆ-ŚWIERCZYŃSKA ${ }^{1}$, DOMINIKA ŚWIERCZYŃSKA-MACHURA ${ }^{1}$, DOROTA CHOMICZEWSKA-SKÓRA ${ }^{1}$, BEATA KRĘCISZ ${ }^{2}$, and JOLANTA WALUSIAK-SKORUPA ${ }^{1}$}

${ }^{1}$ Nofer Institute of Occupational Medicine, Łódź, Poland

Department of Occupational Diseases and Environmental Health

${ }^{2}$ Medical University in Kielce, Kielce, Poland

Department of Health Sciences

\begin{abstract}
Objectives: Manicurists are exposed to various chemicals in nail and skin care products and may develop ocular, nasal, respiratory or skin adverse reactions to them. To investigate the occurrence of ocular, nasal, respiratory and skin problems among manicurists and to identify their causal factors, particularly allergic etiology and occupational origin. Material and Methods: Manicurists employed in beauty salons in the central region of Poland were invited to fill in the questionnaire and undergo medical examination, skin prick tests with common aeroallergens, patch tests with European Baseline Series and (Meth)Acrylates Series-Nails and spirometry. Results: In the questionnaire adverse nasal symptoms were reported by $70 \%$, ocular - by $58 \%$, respiratory - by $42 \%$, hand eczema - by $43 \%$ of manicurists. In the medical interview, the frequency of those complaints was lower: nasal ones $-41 \%$, ocular $-24 \%$, cough $-18 \%$, hand skin dryness $-20 \%$, hand eczema $-6 \%$. Cough and hand skin dryness occurred significantly more frequently than in the case of controls. Contact allergy was found for $41 \%$ of manicurists and 35\% of controls. The prevalence of nickel sensitization was high in both groups (38\% and 27\%, respectively). Only 3 manicurists reacted to (meth)acrylates. The frequency of atopic diseases was similar in compared groups. Irritant nasal and respiratory reactions were significantly more prevalent among manicurists (nasal - 18\% vs. $2 \%$, $\mathrm{p}<0.01$; respiratory $-18 \%$ vs. $1 \%, \mathrm{p}<0.001$ ). Work-related nasal irritant reactions were finally diagnosed for $19 \%$, ocular ones - for $13 \%$, respiratory - for $18 \%$ and within hand skin - for $23 \%$ of manicurists. Conclusions: The frequency of workattributed irritant mucosal and skin symptoms among manicurists is high. Exposure to acrylates is an important source of mucosal irritant reactions while occlusive gloves cause irritation of hand skin. The prevalence of nickel allergy among Polish females is high. Int J Occup Med Environ Health 2017;30(6):887-896
\end{abstract}

Key words:

Manicurists, Beauty salons, Occupational exposure, Screening, Allergy symptoms, Acrylates

Funding: financial support for this work was obtained from local statutory funds IMP 11.2 entitled "Skin and respiratory diseases in employees of beauty salons the type and prevalence of lesions, diagnosis, predisposition, prevention" from Nofer Institute of Occupational Medicine, Lódź, Poland. Grant/Project manager: Prof. Marta Kieć-Świerczyńska, M.D., Ph.D.

Received: March 8, 2016. Accepted: October 25, 2016.

Corresponding author: M. Kieć-Świerczyńska, Nofer Institute of Occupational Medicine, Department of Occupational Diseases and Environmental Health, św. Teresy 8, 91-348 Łódź, Poland (e-mail: marswier@imp.lodz.pl). 


\section{INTRODUCTION}

Manicurists are exposed to various chemical ingredients found in nail and skin care products and may develop mucosal (ocular, nasal, respiratory) and cutaneous adverse reactions to them. Health effects from nail salons result from either airborne exposure to volatile chemicals, dusts and vapor or from direct skin or mucosa contact with various substances. They include occupational asthma, pulmonary edema, mucosal irritation of eyes, mouth, nose, throat and skin reactions such as allergic or irritant contact dermatitis or contact urticaria. Among chemicals reported as responsible for allergic and/or irritant reactions there are for example (meth)acrylates, polymer resins and their plasticizers, disinfectants, fragrances, colorants, rubber components, solvents and diluents [1].

The aim of the study has been to investigate the occurrence of ocular, nasal, respiratory and skin problems among manicurists and to identify their causal factors, in particular allergic etiology and occupational origin, furthermore to assess the frequency of contact allergy to occupational and non-occupational allergens and to evaluate their clinical relevance.

\section{MATERIAL AND METHODS}

Participants of the study were recruited from amongst manicurists employed in beauty salons in the central region of Poland (Łódź city and their surroundings). Invitations with the questionnaire were sent to 150 beauty salons. In the questionnaire manicurists were asked about length of employment, occupational exposure to skin and nail care products, use of protective gloves, occurrence of skin, ocular, nasal and respiratory symptoms. Respondents were also invited to undergo the medical interview, examination and additional tests. In the interview, individuals were asked about ocular, nasal, respiratory and skin symptoms and their connection with work. Then, they underwent physical examination and dermatological assessment. Additional tests included: skin prick tests with common aeroallergens - house dust mites, pollens, fungi (Allergopharma, Germany; Stallergenes, France), patch tests with European Baseline Series and (Meth)Acrylates Series - Nails (Chemotechnique Diagnostics, Vellinge, Sweden) and spirometry with the use of Spirometer Micro Lab ML 350 (Micro Medical Ltd., England). Taking into account data from the interview, results of physical (including dermatological) examination and additional tests, we made an attempt to establish final diagnosis and categorize reported or noted ocular, nasal, respiratory and skin symptoms into allergic, atopic, irritant, occupational or non-occupational.

The interview, medical examination, patch tests and skin prick tests as above were also performed for the control group and results of those investigations were compared between the study group and controls, using Fisher's exact test.

The study protocol was approved by the local ethics committee. All participants gave written informed consents for participation in the study.

\section{RESULTS}

\section{Questionnaire}

One hundred forty-five manicurists, all females, from 108 beauty salons, aged from 21 to 64 years old (mean age $35.43 \pm 9.93$ ), took part in the questionnaire study. The average time of employment as a manicurist was $9.25 \pm 7.8$ years (from 0.5 to 42 years). During job duties participants were exposed to various skin and nail care products, including nail polishes, nail-polish removers, nail hardeners, cuticle removers, hand and foot creams. Occlusive gloves were used in the workplace by 144 manicurists. One hundred and five (73\%) of them reported using latex gloves, 65 - vinyl, 27 - nitryl gloves. Fifty-eight participants used various types of gloves (alternately latex, vinyl and nitryl). According to data from 143 manicurists, mean time of using protective gloves during the working shift was $3.44 \pm 1.8 \mathrm{~h}$ (minimum: $0.5 \mathrm{~h}$, maximum: $11 \mathrm{~h}$ ). 


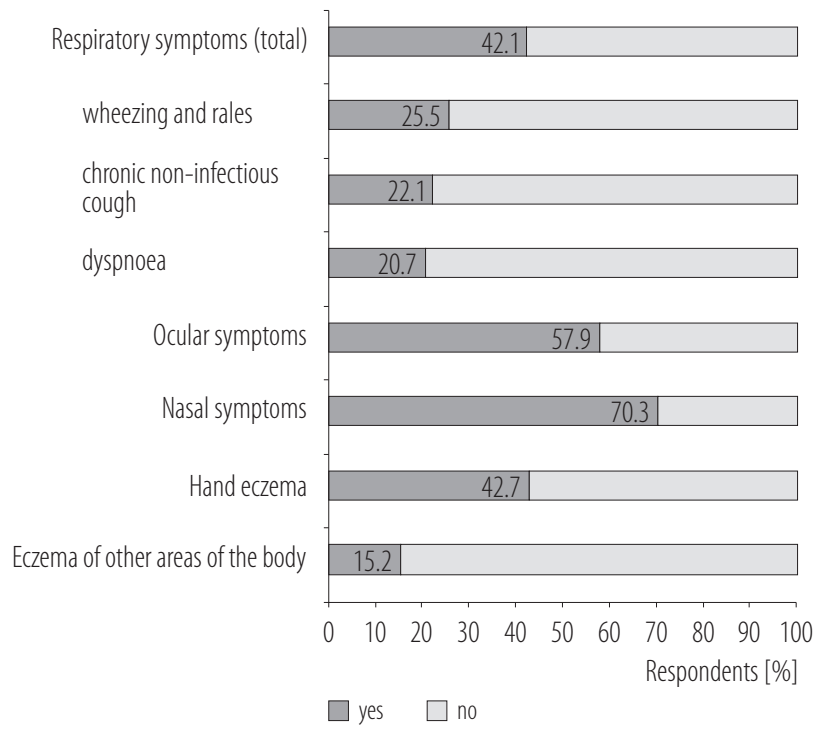

Fig. 1. Frequency of respiratory, ocular, nasal symptoms and eczema reported in the questionnaire by study group manicurists employed in beauty salons

The frequency of reported ocular symptoms (defined as itching, redness of the eyes, tearing), nasal (itching, sneezing, rhinorrhea) and respiratory symptoms (wheezing and rales, chronic non-infection related cough, dyspnea) as well as the prevalence of eczematic skin lesions (defined as skin redness, papules, vesicles, accompanied with itching), in particular hand eczema, are shown in the Figure 1.

\section{Interview}

Out of the 145 participants who completed the questionnaire, 93 ones also gave consents to undergo the medical interview, examination and additional tests. Ninety-three women, aged from 22 to 58 years old (mean age 33.39 \pm 9.11 ) were interviewed in our center by a physician. Twenty-two (24\%) participants reported ocular symptoms such as tearing, dryness, foreign body sensation, redness and/or itching of the eyes. In opinions of 10 interviewees, those symptoms were related to occupational duties and occupational exposure.

Nasal symptoms were reported by $38(41 \%)$ participants, including runny nose, sneezing, stuffy nose, dryness and/ or burning sensation of nasal mucosa, loss of smell. Nineteen individuals suggested the relationship between their symptoms and work.

Dyspnoea and cough were reported by 11 (12\%) and 17 (18\%) participants, respectively. In the opinion of 7 persons with dyspnoea and 12 with cough, symptoms were related to their job duties. Participants associated ocular, nasal and respiratory symptoms in particular with exposure to nail dust, acrylic products, nail-polish removers, disinfectants and nail glues.

Twenty-two (24\%) manicurists complained of skin lesions localized within hands such as dryness and roughness of hand skin, eczematic lesions (redness, papules, vesicles, crackles) and/or itching and burning sensation of the hand skin. Among those 22 individuals, 20 were convinced that their job duties and workplace exposure caused skin problems. As the most important causal factors of skin dryness or hand eczema the following agents were indicated: using occlusive gloves, mainly latex ones (11 persons), frequent hand washing, exposure to disinfectants, nail-polish removers.

Among other work-related skin problems there were also itching of skin of the forearms and dryness and redness of skin of the face, particularly periorbicularis areas, attributed mainly to exposure to dusts and acrylic materials. Furthermore, 8 participants reported other health problems associated with job duties: headaches, dryness of the throat, dizziness and/or nausea.

Ocular, nasal, respiratory and skin symptoms were also investigated in the control group consisting of 77 women, office workers or students, non-exposed to irritant and/or allergic factors in a workplace or at university. The group consisted of individuals who were 18-59 years old (mean \pm standard deviation $=34.83 \pm 10.77$ ). Their contact with nail care products was as follows: 70 females used to paint their nails by themselves at home, 28 were at least once subjected to manicure and/or pedicure in beauty salons, to 20 of them artificial nails were applied (in 18 - acrylic nails). 
Table 1. Frequency of ocular, nasal, respiratory and hand skin symptoms in the study group (manicurists employed in beauty salons) and control group according to the interview with physician

\begin{tabular}{|c|c|c|c|}
\hline \multirow[t]{2}{*}{ Symptom } & \multicolumn{2}{|c|}{$\begin{array}{c}\text { Respondents } \\
(\mathrm{N}=170) \\
{[\mathrm{n}(\%)]}\end{array}$} & \multirow[t]{2}{*}{$\mathrm{p}$} \\
\hline & $\begin{array}{l}\text { study group } \\
(\mathrm{N}=93)\end{array}$ & $\begin{array}{l}\text { control group } \\
(\mathrm{N}=77)\end{array}$ & \\
\hline Ocular symptoms & $22(24)$ & $27(35)$ & n.s. \\
\hline Nasal symptoms & $38(41)$ & $25(32)$ & n.s. \\
\hline \multicolumn{4}{|l|}{ Respiratory symptoms } \\
\hline dyspnea & $11(12)$ & $7(9)$ & n.s. \\
\hline cough & $17(18)$ & $2(3)$ & $<0.01$ \\
\hline \multicolumn{4}{|l|}{ Hand skin symptoms } \\
\hline dryness, roughness & $19(20)$ & $5(6)$ & $<0.05$ \\
\hline
\end{tabular}

n.s. - not statistically significant.

Table 2. Frequency of work-related reactions/symptoms in the study group - manicurists exposed and non-exposed to acrylic nails

\begin{tabular}{|c|c|c|c|}
\hline \multirow{2}{*}{ Symptom } & \multicolumn{2}{|c|}{$\begin{array}{l}\text { Study group } \\
(\mathrm{N}=93) \\
{[\mathrm{n}(\%)]}\end{array}$} & \multirow{2}{*}{$\mathrm{p}$} \\
\hline & $\begin{array}{l}\text { exposed } \\
\text { to acrylic nails } \\
(\mathrm{N}=66)\end{array}$ & $\begin{array}{l}\text { non-exposed } \\
\text { to acrylic nails } \\
\quad(\mathrm{N}=27)\end{array}$ & \\
\hline Ocular, nasal, respiratory irritant reactions & $24(36)$ & $7(26)$ & $<0.01$ \\
\hline Hand symptoms (dryness, roughness, eczematic lesions) & $18(27)$ & $5(18)$ & $<0.05$ \\
\hline
\end{tabular}

Comparison of frequency of ocular, nasal, respiratory and hand skin symptoms in the examined and control group is shown in the Table 1.

According to the interview 73 examined manicurists (76\%) within their job duties applied artificial nails (71 at present and 2 in the past), out of whom 66 acrylic nails (58 at present, 8 in the past). Six persons reported discontinuation of acrylic nails application due to smell or "suffocating vapor." The statistical analysis showed that work-related ocular, nasal and respiratory irritant reactions as well as work-related hand skin symptoms were significantly more frequent among manicurists performing acrylic nails application (Table 2).

\section{Physical examination}

In the case of physical examination of respiratory function, no abnormalities were found for any individuals, neither in the examined nor in the control group. Dermatological assessment revealed some abnormal signs within skin of the hands for 11 manicurists: dryness (particularly of interdigital spaces), hyperkeratosis and fissures, flat warts, naevus flammeus or callus. No abnormalities within skin of the hands were found in the control group. Other skin abnormalities detected among manicurists and controls included predominantly acne of face and/or trunk, numerous melanocytic naevi, keratosis pilaris and in isolated cases - pityria- 
Table 3. Positive patch tests reactions in the study group (manicurists employed in beauty salons) and control group

\begin{tabular}{|c|c|c|c|}
\hline \multirow{2}{*}{ Allergen } & \multicolumn{2}{|c|}{$\begin{array}{c}\text { Respondents } \\
(\mathrm{N}=170) \\
{[\mathrm{n}(\%)]}\end{array}$} & \multirow[t]{2}{*}{$\mathrm{p}$} \\
\hline & $\begin{array}{l}\text { study group } \\
(\mathrm{N}=93)\end{array}$ & $\begin{array}{l}\text { control group } \\
(\mathrm{N}=77)\end{array}$ & \\
\hline Potassium dichromate $0.5 \%$ pet. & $4(4)$ & 0 & n.s. \\
\hline Cobalt chloride $1 \%$ pet. & $6(6)$ & $4(5)$ & n.s. \\
\hline Nickel sulfate 5\% pet. & $35(38)$ & $21(27)$ & n.s. \\
\hline Balsam Peru 25\% pet. & 0 & $1(1)$ & n.s. \\
\hline Quaternium $151 \%$ pet. & $1(1)$ & $1(1)$ & n.s. \\
\hline Thimerosal $0.1 \%$ pet. & $9(10)$ & $8(10)$ & n.s. \\
\hline Copper sulfate $2 \%$ pet. & $5(5)$ & $6(8)$ & n.s. \\
\hline Palladium chloride $2 \%$ pet. & $14(15)$ & $9(12)$ & n.s. \\
\hline 2-Hydroxyethyl methacrylate $2.0 \%$ pet. & $1(1)$ & 0 & n.s. \\
\hline 2-Hydroxypropyl methacrylate $2.0 \%$ pet. & $1(1)$ & 0 & n.s. \\
\hline Triethyleneglycol dimethacrylate $2.0 \%$ pet. & $1(1)$ & 0 & n.s. \\
\hline Trimethylolpropane triacrylate $0.1 \%$ pet. & $2(2)$ & 0 & n.s. \\
\hline Tetrahydrofurfuryl methacrylate $2.0 \%$ pet. & $1(1)$ & 0 & n.s. \\
\hline
\end{tabular}

n.s. - not statistically significant.

sis versicolor, melasma, psoriatic lesions, redness and swelling of the eyelids.

\section{Additional tests}

In the examined group, skin prick tests were positive for 34 individuals $(36 \%)$, and in the case of $12(13 \%)$ the tests proved numerous aeroallergens. In the control group, 23 participants (30\%) showed positive reactions in skin prick tests.

Contact allergy, i.e., at least one positive reaction in patch tests was found among 38 manicurists (41\%) and 27 controls $(35 \%)$. The most frequent allergens in both groups were metals: nickel and palladium. Ninety-eight percent of the examined group and $89.6 \%$ of controls had ears or other parts of the body pierced. Twenty-seven manicurists from among 35 allergic to nickel reported eczematic lesions in skin areas exposed to metal jewellery or metal clothing accessories, which indicates that clinical relevance of nickel allergy was $77 \%$. In the control group positive reactions to nickel were relevant in $76 \%$ of those 4 tested. In the case of 3 manicurists positive reactions to (meth) acrylates were noted but they were clinically relevant only for 1 person. Results of patch testing are shown in the Table 3. No abnormalities were found in spirometry of any participant.

\section{Final diagnosis}

Final diagnoses established for manicurists and in the control group are shown in the Table 4.

\section{DISCUSSION}

In this study, we investigated the frequency of ocular, nasal, respiratory and skin symptoms, in particular workrelated ones, among manicurists. Any similar screening 
Table 4. Final diagnosis of health problems in the study group (manicurists employed in beauty salons) and control group causal factors of symptoms

\begin{tabular}{|c|c|c|c|}
\hline \multirow[t]{2}{*}{ Diagnosis } & \multicolumn{2}{|c|}{$\begin{array}{c}\text { Respondents } \\
(\mathrm{N}=170) \\
{[\mathrm{n}(\%)]}\end{array}$} & \multirow[t]{2}{*}{$\mathrm{p}$} \\
\hline & $\begin{array}{l}\text { study group } \\
(\mathrm{N}=93)\end{array}$ & $\begin{array}{l}\text { control group } \\
(\mathrm{N}=77)\end{array}$ & \\
\hline \multicolumn{4}{|l|}{ Ocular symptoms } \\
\hline allergic conjunctivitis & $7(7)$ & $14(18)$ & n.s. \\
\hline ocular irritant reactions & $12(13)$ & $8(10)$ & n.s. \\
\hline work-related & $12(13)$ & 0 & $<0.01$ \\
\hline overlapping with allergic conjunctivitis & $2(2)$ & & \\
\hline exclusively & $10(11)$ & & \\
\hline others & $5(5)$ & $5(6)$ & n.s. \\
\hline \multicolumn{4}{|l|}{ Nasal symptoms } \\
\hline allergic rhinitis & $16(17)$ & $15(19)$ & n.s. \\
\hline nasal irritant reactions & $18(19)$ & $2(3)$ & $<0.01$ \\
\hline work-related & $18(19)$ & 0 & $<0.001$ \\
\hline overlapping with allergic rhinitis & $6(6)$ & & \\
\hline exclusively & $12(13)$ & & \\
\hline chronic sinusitis & $1(1)$ & $1(1)$ & n.s. \\
\hline others & $9(10)$ & $7(9)$ & n.s. \\
\hline \multicolumn{4}{|l|}{ Respiratory symptoms } \\
\hline asthma & $5(5)$ & $3(4)$ & n.s. \\
\hline respiratory irritant reactions & $17(18)$ & $1(1)$ & $<0.001$ \\
\hline work-related & $17(18)$ & 0 & $<0.001$ \\
\hline overlapping with asthma & $2(2)$ & & \\
\hline exclusively & $15(16)$ & & \\
\hline post-infectious bronchial hyperreactivity & 0 & $1(1)$ & n.s. \\
\hline smoking-related symptoms & $1(1)$ & 0 & n.s. \\
\hline others & $2(2)$ & $3(4)$ & n.s. \\
\hline \multicolumn{4}{|l|}{ Skin symptoms } \\
\hline allergic contact dermatitis & $28(30)$ & $17(22)$ & n.s. \\
\hline work-related (acrylates) & $1(1)$ & 0 & n.s. \\
\hline non-work related (nickel, Quaternium 15) & $27(29)$ & $17(22)$ & n.s. \\
\hline $\begin{array}{l}\text { irritant contact dermatitis / irritant skin lesions } \\
\text { within hands (dryness, roughness) }\end{array}$ & $21(23)$ & $9(12)$ & n.s. \\
\hline work-related & $21(23)$ & 0 & $<0.001$ \\
\hline non-work related & 0 & $9(12)$ & $<0.001$ \\
\hline atopic dermatitis & $3(3)$ & $1(1)$ & n.s. \\
\hline
\end{tabular}

n.s. - not statistically significant. 
inquiry comprising at the same time the questionnaire, medical examination and selected allergy tests had not been performed before in that occupational group. Results of the questionnaire suggested very high frequency of self-reported symptoms, in particular nasal (reported by $70 \%$ participants), ocular $(58 \%)$ and hand eczema (43\%). But during the personal medical interview those complaints were verified and some of them were recognized as irrelevant because of their extremely episodic character and low intensity. That is why the prevalence of respective symptoms differs between the questionnaire and medical interview and is much higher when the first source of information is analyzed.

According to the medical interview adverse ocular and nasal symptoms were reported for $24 \%$ and $41 \%$ of manicurists, respectively, and their frequency did not differ significantly between the examined and control group. From among respiratory symptoms, only the prevalence of cough was significantly higher among manicurists than in the control group (18\% vs. 3\%). Dryness and roughness of the hand skin also appeared to be significantly more frequent among manicurists and it was reported by $20 \%$ of them but only by $6 \%$ of controls. Physical examination showed dryness of skin of the hands only among manicurists, not in the control group. It may be assumed that these last findings reflect the negative effect of manicurist duties on the respiratory and skin function.

We did not find any statistically significant difference in frequency of contact allergy between manicurists and controls. However, attention should be paid to a high percentage of positive reactions to nickel in patch testing. Thirty-eight percent of manicurists were sensitized to that allergen while in the control group a slightly lower number of positive reactions was found, i.e., 27\%. In both groups clinical relevance of patch test reactions to nickel was high and it was found in about 76-77\%.

Taking into consideration the final diagnosis, both in the examined and in control group, many ocular and na- sal symptoms could be attributed to atopy and recognized as allergic conjunctivitis or/and rhinitis. The frequency of those diseases did not differ between compared groups. However, when symptoms appeared in clear correlation with exposure to chemical or physical factors (chemicals especially volatile ones, dusts, stimuli as cold or light), they were classified as irritant both in atopics and nonatopics. We found a statistically significant difference between the prevalence of nasal and respiratory irritant reactions among manicurists and controls. Moreover, in the case of manicurists almost all those reactions were the effect of exposure to various factors in the workplace. In the case of atopic individuals, those reactions quite often overlapped with atopic symptoms. It is also worth noting that irritant skin lesions of hands were attributed to occupational duties in the case of all examined manicurists. These findings also indicate the negative effect of work environment on manicurists health.

Data from literature on ocular, nasal, respiratory and skin problems among manicurists is not numerous but some information from recent years has shown that work-related adverse health effects are not rare among beauticians. It should be emphasized that the most available data refers to skin disorders while other symptoms were less frequently reported and investigated. For example, the British report from 2014 based on THOR-EPIDERM data placed beauticians among occupations with the highest rates of occupational dermatoses, with 64 cases per 100000 workers per year in 2004-2013 [2]. Beauticians were also classified as high-risk female occupations regarding the risk of severe occupational contact dermatitis after the analysis of thousands of such cases from Denmark [3].

In Warshaw et al. study, allergic or irritant contact dermatitis appeared among 37\% of examined cosmetologists [4]. Kwok et al. found an increase in cases of occupational dermatitis associated with acrylates in beauticians over 15 years in Great Britain [5]. In Ramos et al. study, in a group of patients with occupational allergic contact 
dermatitis caused by acrylates and methacrylates, beauty technicians working with artificial nails were the most affected group and accounted for $80 \%$ of all occupational cases [6]. In our study work-related allergic contact dermatitis was a rare phenomenon (only one person) but occupational irritant skin reactions were much more common because they were recognized for $22 \%$ of manicurists.

Available case reports of occupational disorders among beauticians include descriptions of occupational allergic or irritant reactions to various chemicals, manifested by contact dermatitis (including cases of airborne type), more infrequently urticaria or angioedema [7-18]. Studies and case reports mentioned above showed that acrylates were the most important reasons for ill health among beauticians.

Surprising as it was, among our 93 patch-tested manicurists only 3 individuals sensitized to (meth)acrylates were found, with clinical relevance only in 1 case. That low frequency of allergy to those chemicals may be undoubtedly explained by the screening type of our study. Apart from (meth)acrylates, other causal factors of skin lesions in beauticians, for example orangewood [7], plant allergens [11], fragrances (particularly citral) [19], metals, formaldehyde, preservatives and wax [9] could also be mentioned.

Ocular, nasal and respiratory disorders among beauticians and in related occupations were less frequently reported. They include cases of asthma induced by (meth)acrylates [20-22] or exacerbations of preexisting asthma for individuals sensitized to acrylates [15]. Kreiss et al. found an increased risk of asthma with onset during employment among cosmetologists, attributable to their exposure to sensitizers and irritants [23]. In Great Britain, according to the Health and Occupation Research (THOR) database, 11 cases of occupational asthma among beauticians were reported in 1996-2011, attributed to acrylates, dyes, nail glues and nail extruder [5]. Cases of work-related rhinitis were also reported, as caused by acrylates [12] or plant allergens [11]. Mucosal irritation of the eyes, nose, mouth and throat seem to be quite a common problem among cosmetologists exposed to volatile substances and dusts [1].

For example, in the questionnaire study conducted in the USA, $32 \%$ of podiatrists reported respiratory disorders, including not only asthma, sinusitis, repeated chest infections, but also persistent cough and nasal irritant reactions, similarly as in our examined group [24]. Selfreported respiratory symptoms were indicated as common work-related health effects in Vietnamese-American nail salon workers in Roelofs study [25]. Reutman et al. pilot findings suggested that among nail salon workers lung function and airway inflammation may be adversely influenced by work environment, possibly by contact with (meth)acrylates [26]. This could be in accordance with our observations that work-related irritant ocular, nasal, respiratory and skin symptoms were more frequent among manicurists exposed to acrylic nails.

It should be emphasized that many mucosal and skin irritant reactions in the case of manicurists could be prevented and avoided by using protective measures such as efficient ventilation systems and personal protective equipment such as goggles, masks and gloves, especially when exposure to volatile substances or dusts (for example nail dust) occurs. In our study nitrile or vinyl gloves were better tolerated than latex ones and they could be recommended for manicurists.

\section{CONCLUSIONS}

The frequency of work-attributed ocular, nasal, respiratory and hand skin symptoms among manicurists is high, and mostly of irritant origin. Exposure to acrylates is an important source of mucosal irritant reactions among manicurists while exposure to occlusive gloves, particularly latex ones, frequently cause irritation of skin of the hands. The prevalence of nickel allergy among Polish females is high. 


\section{REFERENCES}

1. Engasser PG, Maibach HI, Tiet T, Taylor JS. Cosmetologists. In: Rustemeyer T, Elsner P, John SM, Maibach HI, editors. Kanerva's occupational dermatology. 2nd ed. Vol. 3. Berlin, Heidelberg: Springer-Verlag; 2012. p. 1381-8.

2. Health and Safety Executive. Work-related skin diseases in Great Britain 2014 [Internet]. London: The Executive; 2014 [cited 2016 Feb 13]. Available from: http://www.hse.gov.uk/ statistics/causdis/dermatitis/skin.pdf.

3. Schwensen JF, Fischer Friis U, Menné T, Duus Johansen J. One thousand cases of severe occupational contact dermatitis. Contact Dermatitis. 2013;68:259-68, https://doi.org/10. 1111/cod.12045.

4. Warshaw EM, Wang MZ, Mathias CG, Maibach HI, Belsito DV, Zug KA, et al. Occupational contact dermatitis in hairdressers/cosmetologists: Retrospective analysis of North American Contact Dermatitis Group data. Dermatitis. 2012;23:258-68, https://doi.org/10.1097/DER.0b013e318 $273 \mathrm{a} 3 \mathrm{~b} 8$.

5. Kwok C, Money A, Carder M, Turner S, Agius R, Orton D, et al. Occupational disease in beauticians reported to The Health and Occupation Research (THOR) network from 1996 to 2011. Clin Exp Dermatol. 2014;39:590-5, https://doi. org/10.1111/ced.12367.

6. Ramos L, Cabral R, Gonçalo M. Allergic contact dermatitis caused by acrylates and methacrylates - A 7-year study. Contact Dermatitis. 2014;71:102-7, https://doi.org/10.1111/ cod.12266.

7. Brun R. Contact dermatitis to orangewood in a manicurist. Contact Dermatitis. 1978;4:315, https://doi.org/10.1111/ j.1600-0536.1978.tb04582.x.

8. Freeman S, Lee MS, Gudmundsen K. Adverse contact reactions to sculptured acrylic nails: 4 case reports and a literature review. Contact Dermatitis. 1995;33:381-5, https://doi. org/10.1111/j.1600-0536.1995.tb02071.x.

9. O'Reilly FM, Murphy GM. Occupational contact dermatitis in a beautician. Contact Dermatitis. 1996;35:47-48, https:// doi.org/10.1111/j.1600-0536.1996.tb02267.x.
10. Kanerva L, Lauerma A, Estrander T, Alanko K, HenriksEckerman ML, Jolanki R. Occupational allergic contact dermatitis caused by photobonded sculptured nails and review of (meth)acrylates in nail cosmetics. Am J Contact Dermatitis. 1996;7:109-15, https://doi.org/10.1016/S1046199X(96)90084-6.

11. Rudzki E, Rapiejko P, Rebandel P. Occupational contact dermatitis, with asthma and rhinitis, from camomile in a cosmetician also with contact urticaria from both chamomile and lime flowers. Contact Dermatitis. 2003;49:162, https://doi.org/10.1111/j.0105-1873.2003.0185e.x.

12. Torres MC, Linares T, Hernandez MD. Acrylates induced rhinitis and contact dermatitis. Contact Dermatitis. 2005; 53:114, https://doi.org/10.1111/j.0105-1873.2005.0650a.x.

13. Perale L, de Marchi E, Cecchin E, Sechi LA. Methacrylates allergy in a professional beautician. Contact Dermatitis. 2005;53:181-2, https://doi.org/10.1111/j.0105-1873. 2005.0407n.x.

14. Teik-Jin Goon A, Bruze M, Zimerson E, Goh CL, Isaksson M. Contact allergy to acrylates/methacrylates in the acrylate and nail acrylics series in southern Sweden: Simultaneous positive patch test reaction patterns and possible screening allergens. Contact Dermatitis. 2007;57:21-7, https://doi.org/10.1111/j.1600-0536.2007.01151.x.

15. Lazarov A. Sensitizattion to acrylates is a common adverse reaction to artificial fingernails. J Eur Acad Dermatol Venereol. 2007;21:169-74, https://doi.org/10.1111/j.1468-3083. 2006.01883.x.

16. Roche E, de la Cuadra J, Alegre V. Sensitization to acrylates caused by artificial acrylic nails: Review of 15 cases. Actas Dermosifiliogr. 2008;99:788-94, https://doi.org/10.1016/S00 01-7310(08)74959-7.

17. Andersen SL, Rastogi SC, Andersen KE. Occupational allergic contact dermatitis to hydroxyethyl methacrylate (2-HEMA) in a manicurist. Contact Dermatitis. 2009;61: 48-50, https://doi.org/10.1111/j.1600-0536.2009.01546.x.

18. Maio P, Carvalho R, Amaro C, Santos R, Cardoso J. Letter: Allergic contact dermatitis from sculptured acrylic nails: 
Special presentation with a possible airborne pattern. Dermatol Online J. 2012;18:13.

19. De Mozzi P, Johnston GA. An outbreak of allergic contact dermatitis caused by citral in beauticians working in health spa. Contact Dermatitis. 2014;70:376-88, https://doi. org/10.1111/cod.12173.

20. Sauni R, Kauppi P, Alanko K, Henriks-Eckerman ML, Tuppurainen M, Hannu T. Occupational asthma caused by sculptured nails containing methacrylates. Am J Ind Med. 2008;51:968-74, https://doi.org/10.1002/ajim.20633.

21. Reutman SR, Rohs AM, Clark JC, Johnson BC, Sammons DL, Toennis CA, et al. A pilot respiratory health assessment of nail technicians: Symptoms, lung function, and airway inflammation. Am J Ind Med. 2009;52:865-75, https://doi.org/10.1002/ajim.20751.

22. Sánchez Palacios A, Shaman F, Garciá JA, Sánchez Palacios MA. Prevalence of cosmetic sensitivity among beauticians. Allergol Immunopathol (Madr). 1995;23:148-52.
23. Kreiss K, Esfahani RS, Antao VC, Odencrantz J, Lezotte DC, Hoffman RE. Risk factor for asthma among cosmetology professionals in Colorado. J Occup Environ Med. 2006;48:1062-9, https://doi.org/10.1097/01.jom.0000237348. 32645.eb.

24. Coggins MA, Hogan VJ, Kelly M, Fleming GT, Roberts N, Tynan T, et al. Workplace exposure to bioaerosols in podiatry clinics. Ann Occup Hyg. 2012;56:746-53, https://doi. org/10.1093/annhyg/mer124.

25. Roelofs C, Azaroff L, Holcroft C, Nguyen H, Doan T. Results from a community-based occupational health survey of Vietnamese-American nail salon workers. J Immigr Minor Heath. 2008;10:353-61, https://doi.org/10.1007/s10903-007-9084-4.

26. Reutman SR, Rohs AM, Clark JC, Johnson BC, Sammons DL, Toennis CA, et al. A pilot respiratory health assessment of nail technicians: Symptoms, lung function, and airway inflammation. Am J Ind Med. 2009;52:868-75, https://doi.org/10.1002/ajim.20751.

This work is available in Open Access model and licensed under a Creative Commons Attribution-NonCommercial 3.0 Poland License - http://creativecommons.org/ licenses/by-nc/3.0/pl/deed.en. 